\title{
RIFArtigos/Ensaios
}

\author{
DOI - 10.5212/RIF.v.19.i43.0002
}

\section{Gilmar, homem semente}

Submetido em: 08/11/2021

Maria de Lourdes Macena de Souza ${ }^{1}$

Aceito em: 03/12/2021

RESUMO

Este trabalho compartilha aspectos sensíveis do homem, professor, pesquisador Gilmar de Carvalho na partilha de seus estudos e conhecimentos. Busca dar ênfase a teia rizomática de como, de forma simples e includente, ele foi geminando o reconhecimento das culturas populares, dos seus detentores e produtores desses saberes. 0 artigo traz o olhar de uma artista docente cearense cujas relações com Gilmar foram sempre presentes na luta constante pelos saberes tradicionais, buscando dar visibilidade aos sertões invisíveis e/ou zonas periféricas desses Cearás, por meios comunicacionais e/ou educacionais. No percurso metodológico, utilizei uma pesquisa exploratória em meus laços afetivos com sua obra, numa descritiva de abordagem qualitativa, de como cada uma delas se relacionam a tudo o que sei e faço como artista docente atuante. O resultado trouxe vários encontros dessa profissional mulher, flor de Gilmar, em momentos sensíveis de eterna aprendizagem e gratidão. Estes encontros que ora promovo por meio deste trabalho trouxe-me um Gilmar vivo, presente, atuante, por meio de todo o legado que nos deixou, confirmando mais uma de suas teses: de que é possível permanecermos vivos por meio do que está perpetuado pela escrita. Espero que este possa também sensibilizar a todos e a todas para ver o homem semente Gilmar para além do profissional.

\section{PALAVRAS-CHAVE}

Gilmar de Carvalho; Cultura Popular; Saberes e fazeres; Mestres da Cultura.

\section{Gilmar, seedman}

\begin{abstract}
This paper shares sensitive aspects of the man, professor and researcher Gilmar de Carvalho in sharing his studies and knowledge. It seeks to emphasize the rhizomatic web of how, in a simple and inclusive way, he was germinating the recognition of popular cultures, their

\footnotetext{
${ }^{1}$ Doutora em Artes, artista/docente do IFCE campus Fortaleza, coordenadora do Mestrado Profissional em Artes - PPGARTES IFCE, diretora do Grupo Miraira, Vice-presidente da Comissão Cearense de Folclore, líder do Grupo de Estudos em Cultura Folclórica Aplica da. Correio eletrônico: Iumacena@ifce.edu.br
} 


\section{RIF, Ponta Grossa/ PR Volume 19, Número 43, p.14-30, jul./dez. 2021}

holders and producers of this knowledge. The article brings the point of view of a teaching artist, from Ceará, whose relations with Gilmar were always present in the constant struggle for traditional knowledge, seeking to give visibility to the invisible hinterlands and/or peripheral areas of these Cearás, through communicational and/or educational means. In the methodological path, I used an exploratory research in my affective ties with his work in a descriptive of a qualitative approach, of how each one of them relates to everything I know and do as an active teaching artist. The result brought me several meetings with myself, this professional woman flower of Gilmar, in sensitive moments of eternal learning and gratitude. These meetings, that I now promote through this work, brought me a living Gilmar, present and active through the entire legacy he left for us, confirming yet another of his thesis that it is possible to remain alive through what is perpetuated by writing. I hope this can also sensitize everyone to see the seed man Gilmar beyond the professional.

\section{KEY-WORDS}

Gilmar de Carvalho; Popular Cultures; Knowledge and doing; Master of Culture

\section{Gilmar, hombre semilla}

\section{RESUMEN}

El trabajo prorratea aspectos ssensibles del hombre, professor, investigador Gilmar de Carvalho en el intercambio de sus estudios e conocimientos. Enfatiza la tela balsâmica de como, de manera sensilla e inclusiva, él fue germinando el reconocimiento de las culturas populares, sus poseedores y produtores de estos saberes. El artículo trae la mirada de una artista professora cearense cuyas relaciones con Gilmar foran siempre presentes en la lucha constante por los saberes tradiconales buscando dar visibilidad a las tierras lejanas invisibles o zonas periféricas de los Ceará's por médios comunicacionales y/o educaionales. En la ruta metodológica se usa de una investigación exploratória en sus enlaces afetivos con su obra en una descriptiva de acercarse qualitativa, de como cada una de ellas se relaciona a todo lo que sé y hago como artista professora actuante. El resultado me ha traído muchos encuentros de la profesional mujer flor de Gilmar en momentos sensibles de eterno aprendizaje y gratitud. Los encuentros que ahora hago por médio de este trabajo me ha traído un Gilmar vivo, presente, actuante por medio de todo el legado que nos ha dejado, confirmando más una de sus tesis de que es posible permanecermos vivos por lo que esta perpetuado en la escrita. Rogo que este pueda sensibilizar a todos para mirar al hombre semilla más alla del professional.

\section{PALABRAS CLAVE:}

Gilmar de Carvalho; Cultura Popular; Saberes y haceres; Maestros da la Cultura. 


\section{RIF, Ponta Grossa/ PR Volume 19, Número 43, p.14-30, jul./dez. 2021}

\section{Introdução}

Quando meu encontro presencial/pessoal com Gilmar se deu, já há muito tempo que ele estava comigo a partir de suas obras e de como elas circulavam em minhas aulas e projetos. Interessante que, naquele momento primeiro, parecia que já estávamos ali, um na cozinha do outro tomando café, porque nossos encontros físicos foram menores que os de alma e reconhecimento, pois nos entendíamos como parentes (como dizem os povos originários) de causas e lutas comuns.

É importante deixar claro que apesar de termos vivido na mesma cidade, trabalhando em duas instituições federais vizinhas fisicamente e de ter estudos e interesses em uma vida dedicada às mesmas questões, nunca tivemos tempo para sermos pessoalmente amigos. Sempre admirei Gilmar por tudo o que recebia/recebo de seu pensamento em suas obras. No entanto, é estranho como éramos tão perto e tão longe. Acho que foi isso que consolidou esse grande amor recíproco de admiração e zelo, pois foi assim que sempre senti Gilmar em nossos poucos encontros pessoais, pleno de amor, zelo e admiração pela minha docência e atuação artística e isso me proporcionou confiabilidade nos caminhos escolhidos.

NasCiências Humanas, o rigor científico perpassa por atravessamentos e, no meu caso, neste momento, utilizo a presença da mulher cearense artista conduzindo essa descrição do fenômeno Gilmar de Carvalho, e, nesse trabalho a pesquisa bibliográfica é focada principalmente em sua própria obra, de como ela teceu criações e histórias de vida docente/artística em prol das culturas populares tradicionais do meu estado. O levantamento foi feito em minha biblioteca pessoal e na memória dos momentos vividos com elas e com Gilmar. É preciso que compreendamos a natureza de nossa função neste mundo e de como tudo é passageiro, de como, por meio da ação comunicacional do nosso pensamento, seja ele escrito ou performaticamente revelado em outros trabalhos de criação, como isso nos faz permanecer vivos, mesmo após nossa partida. Isso eu aprendi dolorosamente com Gilmar.

É importante também compartilhar com o leitor o que me levou à decisão de falar sobre isso de uma forma tão pessoal, numa revista acadêmica de folkcomunicação. Fiquei de início pensando o que dizer que ainda não foi dito sobre Gilmar após seu encantamento. Então lembrei de um fato ocorrido durante uma palestra que dei, a convite de Gilmar, durante 


\section{RIF, Ponta Grossa/ PR Volume 19, Número 43, p.14-30, jul./dez. 2021}

o seminário de etnomusicologia em seu evento "I Ceará das Rabecas"(2011) . Na oportunidade, falei sobre os gêneros sonoros tradicionais populares do Ceará e como eles necessitavam do reconhecimento de sua presença nas diversas expressões folks cearenses. Fiquei muito feliz ao ver Gilmar atento na plateia. Ao concluir a participação no seminário, ele me chamou e falou

[...] gostei bastante de sua fala e gostaria muito de poder aprofundar, fazer um mergulho nessas experiências e observações musicais que você traz por meio de uma leitura e como você não a tem, pergunto: quando você vai parar um pouco de dar aula para escrever, publicar? Quando você dá aula você fala para 30, porém uma publicação pode chegar a 300,3 mil ou mais pessoais. Você sabia que todos nós vamos morrer? Sem a escrita, tudo se perde com você após sua partida, porém por meio da obra publicada você além de ter mais alcance poderá estar viva após sua ida (Informação verbal)

Fiquei ali, parada, olhando para ele e pensando que precisava encontrar esse tempo em meio à vida louca de mil tarefas que sempre levei. Já havia tomado conhecimento de algo similar do bonequeiro ${ }^{3}$ Pedro Boca Rica, o grande topador de boi ${ }^{4}$ de Ocara, município do Ceará que fica a duas horas da capital Fortaleza. Ele disse "[...] o Boneco é imortal: o bonequeiro vai, o boneco fica e a história continua..." (MAZULO JUNIOR, 2005, p. 60). Aquela observação feita por Gilmar, segurando o meu braço e ao lado de minha filha, pois ele pediu uma testemunha para o que queria me dizer, trouxe a afirmação de Pedro Boca Rica, além de me acompanhar desde então, e, ao saber de sua morte, a ideia voltou fortemente. Então pensei que seria importante caminhar por esta tese neste texto, e, promover esses encontros que faço agora, revelando esse Gilmar vivo em mim.

\section{Madeira matriz, cultura e memória das artes da tradição, semeando caminhos}

Quando me deparo com os tantos livros que tenho de Gilmar, de seus percursos pela xilogravura e vida de seus xilógrafos, cujas leituras percorri provavelmente, ao saberem de mim - profissional da música e das artes cênicas- perguntariam alguns o que eu queria nessa

\footnotetext{
${ }^{2}$ Seminário Cultura e Tradição - Etno musicologia. Mediador: Juliano Smit. Convidados: Luciana Giffoni, Elba Braga Ramalho e Lourdes Macena. Local: Seminário da Prainha

${ }^{3}$ No Ceará, é como chamamos o artista do Teatro de Animação que para nós é Teatro de Bonecos assim, o Bonequeiro pode criar e ser corpo e voz do seu boneco.

${ }^{4} \mathrm{O}$ que brinca de boi, coloca o boi para brincar, improvisa suas cantigas e atua nele.
} 


\section{RIF, Ponta Grossa/ PR Volume 19, Número 43, p.14-30, jul./dez. 2021}

imersão que é do campo das artes visuais e comunicacionais. No entanto, com certeza, acredito eu, estes não leram Gilmar.

A escrita de Gilmar de Carvalho nos permite ser andarilho como ele, andar lado a lado descobrindo de forma caminhante estes sertões assertivos, errantes e resistentes, que nos ensinam a cada encontro sobre essas formas de vida sempre criadoras. Além de as temáticas abordadas por ele tecerem rizomas em linguagens distintas, que nos vai permitindo um conhecimento plural dos saberes e fazeres tradicionais.

Ancorada em suas obras sempre me senti à sombra do Juazeiro, de um Pé de Tambor ou de uma Umburana, todas juntas ali, a me trazer o que estas "Três árvores" (CARVALHO, 1998) possibilitam aos xilógrafos, como sua invenção poética, raízes monumentaisque cravaram em mim a história e a luta política de Juazeiro do Norte, buscando combater a intolerância, a fome e trazendo o Romeiro e os lugares sacralizados e que envolvem vida e morte dePadre Cícero.

Minhas relações afetivas e de fé com o Padre Cícero veio de minha mãe. A primeira imagem dele que vi estava ao lado de seus demais santos. Desde então, meus estudos culturais sobre a fé do povo estão calcados não somente na história acadêmica descrita, mas também no imaginário, na religiosidade popular do romeiro e na vida peregrina registrada nos folhetos de cordéis. Gilmar soube com maestria fazer isso muito bem. Em Madeira Matriz (1998) prêmio Silvio Romero $1998^{5}$, eu reconheci o mito Padre Cícero, como ele foi e é presença nos folhetos, entendi as romarias, as renovações, os milagres, as infinitas e necessárias lutas políticas junto ao poder das elites e muito especialmente como tudo foi se moldando

pelos contingentes devotos, o modo como a tradição surgiu e se estabeleceu. A sedimentação do diminutivo afetivo de Padre e o sentido arcaico das relações de compadrio, então vigentes, ainda mais com ênfase no Nordeste brasileiro foi se fazendo aos poucos, como a somatória de vários el ementos e atitudes, até que a imagem irretocada se impusesse como um emblema das relações entre o poder e a fé. (CARVALHO, 1998, p. 123)

As imagens dos gravadores foi consolidando fatos a partir de como cada um poeticamente ia se relacionando com acontecimentos e histórias e fazia/faz isso com o entendimento a partir, principalmente, do imaginário popular. Há razões ditas e não

\footnotetext{
${ }^{5}$ MINC/FUNARTE - Centro Nacional do Folclore e Cultura Popular.
} 


\section{RIF, Ponta Grossa/ PR Volume 19, Número 43, p.14-30, jul./dez. 2021}

conhecidas, mas sabidas por meio da obra de Gilmar. “Há todo um repertório que pode até não circular, como deveria, mas que é contado, oralmente e, vivenciado, impregna cada artista, com informações das quais será impossível prescindir na hora da criação" (idem, ibidem, p. 273).

Lendo muitos autores de minha terra, diria que como filha das entranhas sertanejas que sou, somente duas pessoas me trouxeram em sua poética escrita este sertão vivo em mim: Gilmar de Carvalho e Oswald Barroso ${ }^{6}$. Provavelmente devido a isso, essa leitura em sua obra seja sempre um caminhar com eles.

Minhas aulas de campo com minhas turmas em Juazeiro do Norte passaram a ser outra coisa após ler Gilmar. Sua escrita não revela conhecimentos de fora para dentro, mas sim, traz a força pulsante, real, verdadeira, da vida dessas expressões da tradição popular, cuja presença está perpetuada a partir das cenas reveladas nos folhetos, na gravura, nos santeiros e nas diversas paisagens em cerâmica que circulam nas feiras de Juazeiro. Esse reconhecimento esclarecido adentra a academia de uma forma que só Gilmar soube fazer e vai se revelando madeira matriz para muitas coisas que desejamos saber e criar.

Percorrendo Mestres Santeiros (2004) foi possível compreender o universo que formou toda a cosmologia sagrada de nossa religiosidade popular. Nesse emaranhado sincrético reconhece-se os santos do povo, advindos não apenas do catolicismo, mas o que surge também da criação e adoração do que se torna sagrado, apesar de tudo o que foi imposto pela presença católica do português em nosso processo civilizatório. Sem embargo, sabemos que nos Retábulos do Ceará cabem tudo e mais um pouco, mesmo que eles também perpetuem o imagético dos santos trazidos pelos europeus.

Gilmar sai destacando de forma sintética com afinco a subversão da catequese nos aldeamentos indígenas da Paupina, Parangaba, Caucaia, Almofala, a partir do sincretismo necessário; dá destaque às Irmandades negras religiosas e coroação de reis do Congo, no Aracati, Icó e no Crato. Fala também das

Missões, quando padres franciscanos percorriam os sertões investindo sobre os maus costumes, ameaçando a todos com o fogo do inferno e evocando a Missão Abreviada, com suas prédicas maniqueístas que estavam na base do ideário do

\footnotetext{
${ }^{6}$ BARROSO, Raimundo Oswald Cavalcante. Dramaturgo, poeta, jornalista, folclorista cearense autor de várias obras.
} 


\section{RIF, Ponta Grossa/ PR Volume 19, Número 43, p.14-30, jul./dez. 2021}

Antônio Conselheiro de Quixeramobim e Canudos; das práticas filantrópicas do Padre Ibiapina, com seu desprendimento, suas casas de caridade e suas beatas. Foi nesse contexto que se constituíram as ordens de penitentes. Suas flagelações com 'cachos' de lâminas de metal, cilícios e benditos varavam a noite inteira pedindo clemência e louvando São Sebastião, o santo protetor contra a fome, a peste e a guerra. (CARVALHO, 2004, p. 8).

Quando peguei para ler Mestres Santeiros meu desejo era conhecer, compreender um pouco de onde vinham as imagens que eles, os santeiros, talhavam na madeira e como este processo sagrado ocorria para eles, já que aprendi no ambiente familiar que não se joga fora uma imagem, se necessário for, ela deve ser enterrada com respeito. Porém, logo no início do livro, Gilmar foi tecendo os parágrafos como quem reza um terço, e ali a cada conta ia desfiando esse Ceará místico e mítico, sagrado e plural. Foi com ele que aprendi que "estes santeiros fazem santos à imagem e semelhança do que somos e daquilo em que cremos" (idem, ibidem, p. 10).

Com bondade e seriedade, Gilmar vai revelando mundos e pessoas por meio de suas Memórias da Xilogravura. Apesar dessa obra ter sido lançada em 2010, já conheciaWalderêdo, Antonio Batista, Lino, Iraci, Zé Caboclo, Arlindo, Ezígio, Abraão, Stênio, Francorli, Zé Lourenço desde a década de $80 / 90$ do século XX pelas andanças compartilhadas de Gilmar, quando foi demarcando o território da Xilogravura em suas diversas imbricações com outras manifestações. Inclusive, mesmo sem ter conhecido pessoalmente Damásio Paulo, Gilmar com generosidade dedica este livro a esse que foi, segundo ele, "um dos maiores gravadores de todos os tempos [...] As marcas na madeira deixada por Damásio são de uma força, de um equilíbrio e de um impacto que nos deixam aturdido pela sua genialidade" (Idem, ibidem, p. 9). Em cada gravura, em cada folheto revisto a partir da interpretação de Gilmar fui aprofundando impressões, aprendendo outras conexões e dando sentido a um outro Juazeiro, mais profundo e atemporal, pois nele existe uma cosmovisão centrada em começo-meiocomeço, onde a vida, até hoje, corre sempre ligando tudo a um mesmo ponto que é a vida do Padre Cícero "o meu Padim". Ali, Gilmar nos diz do tempo cósmico de peregrinação em um percurso purificador.

Foi com Gilmar que aprendi a ver e ler a xilo "como desencadeadora do processo de transmissão de saberes" (CARVALHO, 2011, p. 70) e que estas "tratam da relação oral/escrito, que se realimentam, num ciclo que nunca se fecha, de narrativas, mitos e crenças que perpassam as mil e uma noites sertanejas" (idem, ibidem, p. 73). Com ele sempre foi fácil 


\section{RIF, Ponta Grossa/ PR Volume 19, Número 43, p.14-30, jul./dez. 2021}

compreender tradição e inovação e de como essa dinâmica vive constantemente perm eando a obra criadora dos artistas do sertão.

Estive com meus alunos em 2011 no Museu do Ceará na exposição "Poetas populares" e no lançamento do livro Xilogravura, doze textos escritos na madeira e Cordel: a voz do verso. Fui para conhecer, refletir, aprender e ensinar através do que era vivido ali. Foi um reencontro com a obra imagética de D. Jesus, Stênio Diniz, Mestre Noza, os versos de Expedito Sebastião da Silva permeados do imaginário da vida Juazeirense e nos pedaços medievais que resistem em suas narrativas. Como se tornou fácil dar ênfase a tantas matrizes para a ação docente e criativa do Teatro de raiz popular. Estava tudo ali pertinho, aproximadas pela arte dos xilógrafos e poetas de Juazeiro do Norte. Foi possível compreender os pontos de ligação histórica da Tipografia São Francisco, José Bernardo e a Lira Nordestina, o grande momento desta última, a partir da chegada da folhetaria de João Martins de Athayde em 1949 e toda a caminhada dos artistas envolvidos nesta Lira Nordestina de grandes contribuições cearenses.

José Bernardo foi o principal editor da literatura de cordel em nosso país e, segundo Gilmar, consolidou os dragões, princesas, amores valentes e apaixonados nas criações de João Pereira, Manoel Lopes, Mestre Noza, Antonio Batista,Walderêdo Gonçalves, entre tantos, tantos e tantos outros. Bom mesmo foi falar e discorrer sobre o Imperador Carlos Magno de coroa e espada presente não apenas nas cantorias, cordéis e xilogravuras, mas também em muitas danças dramáticas ${ }^{7}$ e no teatro de raiz popular (PIMENTEL, 2003) desses sertões que circulam em meio à vida destes devotos brincantes onde há

fé que se manifesta sem condições. Sertão que está dentro de nós, disse um poeta, e que explode na epifania do sol, iluminação que nos conduz a este chão sagrado [...], onde o luminoso é reinventado pelas mãos hábeis dos artistas que são demasiadamente humanos mas que elevam à dimensão do indecifrável mistério (CARVALHO, 2004, p. 12)

Destes sertões, Gilmar revela os mestres do povo por meio de Artes da tradição (2005).Na verdade, esta obra dialoga com outra que sairia no ano seguinte intitulada Mestres da Cultura Tradicional Popular do Ceará (2006). Esses dois trabalhos foram impulsionados pela

\footnotetext{
${ }^{7}$ Termo advindo da Europa e cunhado no Brasil por Mário de Andrade $(1935,1959)$ e utilizad o por Souza (2014).
} 


\section{RIF, Ponta Grossa/ PR Volume 19, Número 43, p.14-30, jul./dez. 2021}

lei de registros dos Mestres da Cultura do Ceará sancionada em $2003^{8}$, durante o governo de Lúcio Alcântara, tendo como secretária de Cultura a professora Cláudia Leitão. Em 2005, eu estava presidindo a CCF - Comissão Cearense de Folclore e buscava por meio desta e com o apoio do IFCE campus Fortaleza, incentivar os estudos dos saberes tradicionais populares. Importante destacar o contexto em que se inseriu essas obras de Gilmar e a importância em meio aos fatos. Desde 2003 que realizávamos no CEFET (hoje IFCE), a especialização em Cultura Folclórica Aplicada, além de termos um grupo de estudos cadastrado no CNPQ com o mesmo nome. Nessa especialização, Gilmar ministrou a disciplina de Literatura de Cordel e, Roberto Benjamim ${ }^{9}$, sobre a Pesquisa em Folclore,entre tantos outros colaboradores como pode ser visto na imagem abaixo.

Figura 1 - Folder Espefolk Turma I - 2003/2004

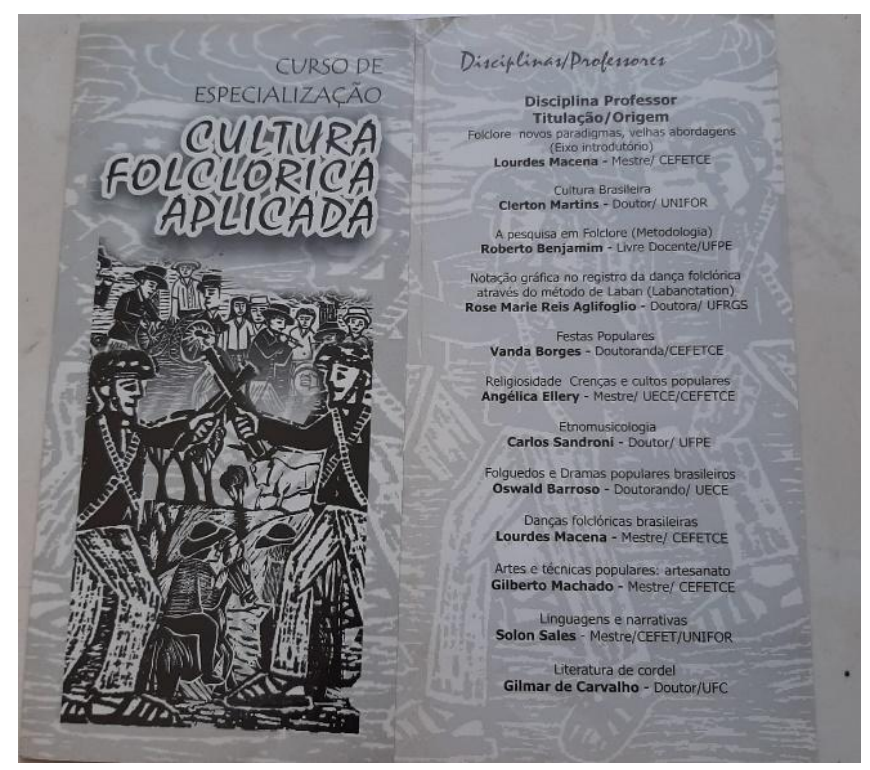

Fonte: Arquivo- CPQT/CEFETCE

Todas essas ações que ocorriam no Ceará corroboravam com o que foi aprovado na Conferência da UNESCO em Paris em outubro de 2003, durante sua 32a sessão, na Convenção para a Salvaguarda do Patrimônio Imaterial, orientando o reconhecimento recíproco,

\footnotetext{
${ }^{8}$ Lei 13.351, de 22.08.03 -m Registro dos Mestres da Cultura Tradicional Popular do Estado do Ceará. Disponível em: https://www.al.ce.gov.br/legislativo/tramitando/lei/13351.htm.

${ }^{9}$ Roberto Benjamin foi Presidente da Comissão Pernambucana de Folclore e da Comissão Nacional e foi também livre docente do Programa de Pós-graduação em Extensão Rural da Universidade Federal Rural de Pernambuco. Estudioso do Folclore e da Folkcomunicação.
} 


\title{
RIF, Ponta Grossa/ PR Volume 19, Número 43, p.14-30, jul./dez. 2021
}

proteção e cooperação para valorização destes bens. Motivados por tudo isso a SECULTE/CE realiza o I Encontro Mestres do Mundo para dar conhecimento aos Mestres registrados e reconhecidos pelo estado, e nós, da Comissão Cearense, realizamos o I Congresso Cearense de Folclore como destacou o jornal Diário do Nordeste,

\begin{abstract}
Antecipando e aquecendo para o I Encontro dos Mestres do Mundo, de 21 a 23 de agosto, Limoeiro sediará o I Congresso Cearense de Folclore. Com a temática "Folclore, tradição dinâmica - novas abordagens", o evento acontec erá na Faculdade de Filosofia Dom Aureliano Matos (Fafidam). Na programação, debates, seminários, mesas-redondas, aulas-espetáculo e muitas a presentações folclóricas. Segundo a Presidente da Comissão Cearense de Folclore (CCF), Lourdes Macena, o encontro tem o objetivo de possibilitar o envolvimento de pesquisadores e estudiosos cearenses e brasileiros com os mais recentes estudos e pesquisas, ampliando e favorecendo a discussão dos novos paradigmas que norteiam o saber popular, além de estimular a participação de jovens estudiosos [...]Os grupos de trabalho da programação serão divididos nas áreas de Oralidade, Artesanato e Lúdica Infantil, Folkcomunicação e EAD de Cultura Popular, Etnomusicologia, Folclore, Turismo e Geografia Cultural, Religiosidade Popular, Festas Populares, Danças e Folguedos. (Diário do Nordeste, $2 / 8 / 2005)^{10}$
\end{abstract}

As duas obras de Gilmar citadas $(2005,2006)$ coadunam com todas essas ações de revelação desses territórios invisibilizados, com a força criativa humana dos Mestres da Cultura e seus saberes com a beleza dos encontros promovidos. Artes da Tradição, mestres do povo me possibilitou fazer este passeio incrivel com meus alunos pelos doces Fartes (Sobral), os aboios de D. Dina Vaqueira (Canindé), os licores, bulins e o pife de Seu Alfredo Miranda (Viçosa), as esculturas de Seu Bibi (Canindé), as rezas e curas de Seu Luís José (Juazeiro do Norte), o café de D. Zenilda (Assaré), a obra selada no couro de Expedito Seleiro (Nova Olinda), a beleza da performance de Zé Rainha do Maracatu Rei de Paus (Fortaleza), a voz e a viola de João Alexandre (Juazeiro do Norte), o Boi Ideal de Mestre Panteca (Sobral), Bonecos e Bonequeiros de Ocara, as peças de barro das três Marias da família Cândido (Juazeiro do Norte), as esculturas em madeira de Manuel Graciano (Juazeiro do Norte), a Banda Cabaçal dos Irmãos Aniceto (Crato) e a Lapinha de Maria Tatai (Juazeiro do Norte). Além disso, é possível tecer muitas tramas e conversas sobre altares, oficinas, formas de cozinhar, utensílios da arte utilitária, rendeiras e pescadores, redes de Tucum, a cultura da farinha e do caju, a

\footnotetext{
${ }^{10}$ Disponível em: https://diariodonordeste.verdesmares.com.br/regiao/congresso-de-folcl ore-anteced eeven to-1.718980.
} 


\section{RIF, Ponta Grossa/ PR Volume 19, Número 43, p.14-30, jul./dez. 2021}

força da Pomba Gira na Umbanda, rabecas e pajelanças, entre outras. Um mundo de saberes, lugares e pessoas, tudo ali numa obra só, num fio que se desenrola sem fim.

Enquanto nessa obra Gilmar concentra-se principalmente nos saberes e fazeres, em Mestres da Cultura Tradicional Popular do Ceará, o mote são os Mestres, Tesouros Vivos reconhecidos e diplomados pela SECULT/CE até 2006, ou seja, trinta e seis Mestres. Com fotos de Francisco Sousa, o livro nos fez chegar mais perto de cada mestre, sua vida, seu cantar e seus saberes ancestrais. Gilmar vai trazendo ali a voz de cada um. Suas narrativas como numa contação de histórias, dá destaque por meio de entremeios a estas vozes silenciadas, revelando este imenso tesouro cearense dos homens e mulheres dos reisados, dos repentes, dos Congos, Cordéis e Bandas Cabaçais. Assim, fomos conhecendo melhor Mestre Aldenir, Juca do Balaio, Maria de Lourdes Cândido, Panteca, Margarida Guerreira, Raimundo Aniceto, Doca Zacarias, Joaquim Mulato, Lúcia Pequeno, Walderêdo Gonçalves, Bigode, Miguel, Antônio Hortêncio, Chico, Dona Branca, Cirilo, Dona Dina, Dona Edite, Dona Gerta, Zé Gonçalo, Piauí, Zé Pio, Dona Zilda, Dona Fransquinha, Joviniano Feitosa, Dona Tatai, Pedro Balaieiro, Manuel Graciano, Oliveira, Gilberto Calungueiro, Sebastião Chicute, João Evangelista, Joaquim de Cota, Zé Matias, Antônio Pinto e Zulene Galdino. Diante de tudo isso, digo que a Especialização em Cultura Folclórica, O I Encontro Mestres do Mundo, o I Congresso Cearense de Folclore e essas duas obras de Gilmar de Carvalho, demarcam um momento exitoso de concretudes de lutas para evidenciar e reconhecer os saberes tradicionais e seus detentores no âmbito educacional, comunicacional e patrimonial. Diria que tudo isso evidenciou o que tínhamos e o muito que ainda precisa ser feito.

De todas as obras de Gilmar, a que me trouxe mais encantamento foi sem dúvidas Rabecas do Ceará (2006)e Tirinete - Rabecas da Tradição (2014), esta última vencedora do prêmio Rodrigo Melo Franco de Andrade 27ạ edição, do IPHAN. Sou musicista, filha de sanfoneiro e com familiares cantadores de viola e de músicos de tradição oral. Nunca entendi o descaso dos conservatórios e cursos de formação musical nas universidades que, de certa forma, têm desprezado essa tipologia de música e de instrumentos. Sempre me preocupei com a situação da Rabeca e da Sanfona de 8 baixos (fole de 8 baixos, pé de bode) pela necessidade de visibilidade, reconhecimento e repasse do saber principalmente entre a juventude. O som da Rabeca nos traz os Reisados, Bumba-meu-boi, as Renovações e o forró de raiz das folias sertanejas. Foi a singeleza, sensibilidade e competência de Gilmar que trouxe 


\section{RIF, Ponta Grossa/ PR Volume 19, Número 43, p.14-30, jul./dez. 2021}

a Rabeca para o centro das atenções no urbano e, por meio de sua pesquisa, promoveu toda a espetacularização que ela necessitava para evidenciar a genialidade de seu som e suas possibilidades. Mais que isso, trouxe os rabequeiros demarcando seus territórios, sua vida e particularidades. Eram cento e setenta e cinco rabequeiros revelados na obra citada, além de doze luthiers. Em sua obra, de forma generosa, Gilmar nos possibilita por meio de um $Q R$ code acessar uma playlistpara ouvir os rabequeiros ${ }^{11}$ e édessa forma que em todo o semestre o som das rabecas do sertão do Ceará está presente em minhas aulas de formação de professores.

Como é difícil reler, rever Cem Patativa (2009) agora sem Gilmar. Patativa do Assaré foi o poeta dos poetas, o mestre dos mestres, cujos versos e poesia circulam entre nós e o mantém vivo numa rede rizomática de mil possibilidades servindo, nesse caso, como mais um exemplo da tese de Gilmar sobre a permanência da essência do homem/mulher após sua partida, por meio de sua obra edificada.

Sobre ele e com ele Gilmar lança Patativa do Assaré (2000) e Patativa, poeta pássaro de Assaré (2002). Apesar de possuir muitas obras de Patativa com sua poesia e sua fala, estes livros de Gilmar me trouxeram a vida do poeta para bem perto, como Gilmar sabia fazer bem. Suas entrevistas nos permitem estar ali com ele, fazendo parte também daquelas narrativas como um ouvinte atencioso. Porém, em Cem Patativa (op.cit),Gilmar vai mais além e traça toda a trajetória e legado desse poeta do povo, militante, doutor honoris causada Universidade Estadual do Ceará, da Universidade Federal do Ceará e da Universidade Tiradentes de Sergipe. Seus versos estão em canções, filmes, dissertações, teses e na luta cotidiana sobre as demandas nordestinas. Sobre Gilmar ele assim disse

Doutor Gilmar de Carvalho eu gostei de seu trabalho, estou bastante feliz,/ com a pena milagrosa, você retratou em prosa tudo o que em versos fiz. [...]Quando ouvi sua escrita bem verdadeira e bonita,fiquei de tudo bem certo,/ por onde Deus me guiava você também caminhava me observando de perto.[...] Você me fez renascer e eu preciso agradecer com a simples poesia/ de um poeta de mão grossa que sempre tirou da roça o seu pão de cada dia.[...] Tudo o amigo falou, vejo que nada faltou, além do tema rural,/falou até sobre a crítica que eu fazia da política na campanha eleitoral.[...] Disse a verdade real, vou fazer ponto final e quero nesse momento/ para cumprir meu dever com amor oferecer o meu agradecimento.[...] Tenho oiten ta e nove anos mas não mudei os meus planos, a lucidez e a noção,/ tudo quanto é bom me inspira receba da minha lira o papel da gratidão. (Patativa do Assaré. In: CARVALHO, 2009, s/p)

\footnotetext{
${ }^{11}$ Disponível em: https://www.you tube.com/playlist?list=PLut_fr3TYm5KYbLrtjhElyG5zlJw5cBd_
} 


\section{RIF, Ponta Grossa/ PR Volume 19, Número 43, p.14-30, jul./dez. 2021}

Cresci e me formei lendo, sabendo, vendo e sentindo Patativa do Assaré. Seus versos falavam e dizem de mim, do sertão dos meus ancestrais e também meu, das demandas e luta pela terra, da militância dessa mulher docente freireana. Sua poesia nos favorece, enobrece o povo nordestino, nos ensina a ter autoestima e a lutar contra as injustiças. Quando soube de sua morte em 2002, precisei me apoiar para não cair e chorei copiosamente. Provavelmente por isso senti os textos de Gilmar ali, como bem o disse Patativa, "caminhando com ele, observando bem perto". Gilmar apresenta o mito, a voz, o verso, a genialidade desse poeta do povo, sua trajetória nos cordéis e em múltiplas abordagens, está tudo ali, a memória, a poética e a cronologia de toda uma vida.

Dessa forma, Patativa do Assaré, assim como Gilmar de Carvalho, seguem VIVOS, não apenas em mim, comigo, mas acredito que, nas infinitas salas de aula e em outros lugares com os que gostam de ler por este mundo afora, pois, sua escrita leva nossos saberes e fazeres e discorre sobre o patrimônio imaterial de nosso povo para além do que possamos imaginar. Mais importante que os saberes em si, Gilmar revelou, visibilizou homens e mulheres e muitos territórios desse Ceará de 184 municípios tão pouco conhecidos. Sua obra tem me auxiliado junto à juventude a reconhecer as entranhas sertanejas desse Ceará de serras, mares e sertões, cujas terras no início "nem o donatário quis" (CARVALHO, 2014, p. 264) mesmo assim seguimos, fazemos festa e promovemos o riso irreverente e farto para alimentar o corpo cansado. Apesar disso, Gilmar enfatiza que nossas questões culturais

[...] não se reduzem, nem se resolvem pelo riso, num passe de mágica. Como não se resolvem, também, pela crítica às mídias. Passam pelas discussões sobre o que somos, para saber o que queremos ser. As práticas culturais se desenvolvem ao sabor do mercado, na satisfação das expectativas de lucro. Passam pelas descontinuidades das políticas culturais, onde os gestores ouvem a sociedade civil, para depois fazer o que bem querem, o que cobram seus compromissos ou receitam seus caprichos. [...] este foi um passeio pelos bosques da cultura, um momento para o desencadear das múltiplas reflexões que poderão nos dar um rumo. (CARVALHO, 2014, p. 273)

Este texto citado acima, utilizei em minha aula no Mestrado Profissional em Artes do IFCE, durante a disciplina Matrizes estéticas tradicionais na docência e em processos criativos, no mês de outubro deste ano. Foi uma imersão em nossos elementos fundantes, nossas 


\section{RIF, Ponta Grossa/ PR Volume 19, Número 43, p.14-30, jul./dez. 2021}

marcas, nossas dores e nossas virtudes para compreender de fato o que somos historicamente. Assim, afirmo: Gilmar continua comigo, circulando em tudo o que sou e faço.

Não poderia deixar de destacar a dramaturgia de Gilmar de Carvalho. Sou professora de Teatro e Cultura Popular, disciplina na qual estudamos sobre dramaturgia nordestina. Tomei conhecimento de sua obra Teatro completo (2011), e sai buscando, tentando comprar para utilizar com a turma, fazer uma leitura dramática para conhecer o teor das peças teatrais de sua criação. Não tendo encontrado disponível nas livrarias, liguei para ele procurando saber como fazer, já que uma das peças era Orixás do Ceará e estávamos muito interessadosem estudá-la. Ele pediu meu endereço e, quando cheguei à noite em casa, o livro já estava lá. Gilmar era este ser incrível, pleno de generosidade!

Situação similar ocorreu quando recebi o pesquisador de literatura de Cordel John Rex Amuzu da Universidade francesa de Poitiers a pedido de Roberto Benjamim. Fiz contato para uma possível entrevista com Gilmar, quando menos esperei ele estava no IFCE totalmente disponível e com livros para presentear, coisa que ele adorava fazer.

No dia 29 de agosto deste ano os amigos e amigas de Gilmar realizaram um evento no Passeio Público de Fortaleza, pois foi nesse local que foram colocadas suas cinzas de cremação.

Figura 2 - cartaz

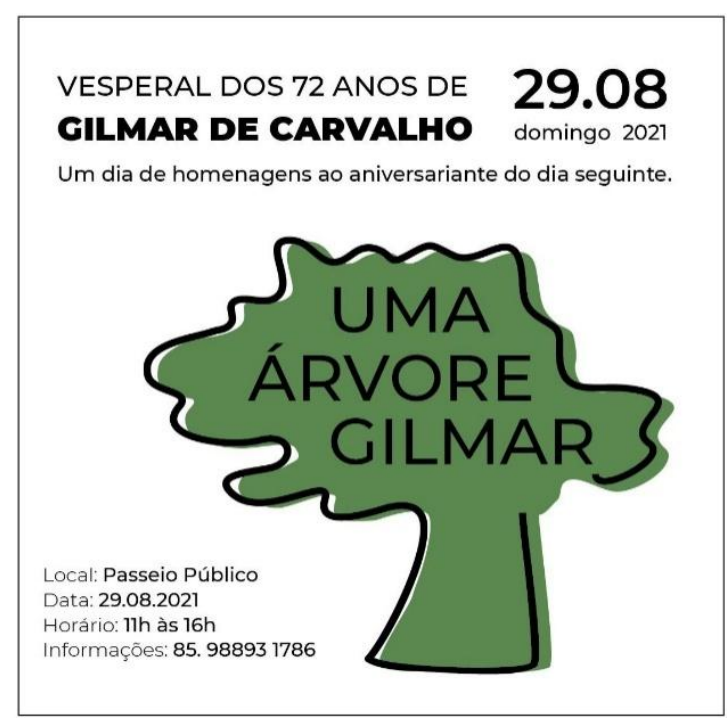

Fonte: movimento flores de Gilmar 


\section{RIF, Ponta Grossa/ PR Volume 19, Número 43, p.14-30, jul./dez. 2021}

Ali, embaixo de um pé de Baobá, árvore milenar potente, poderemos sentir bem perto a presença dele, é um lugar convidativo para se ler e abraçar a vida. Quando penso nele, me vejo assim: amparada naquela grande sombra de saber, nessa "arvore Gilmar" que continua geminando, proliferando frutos culturais.

Figura 3 - Gilmar presente, sempre

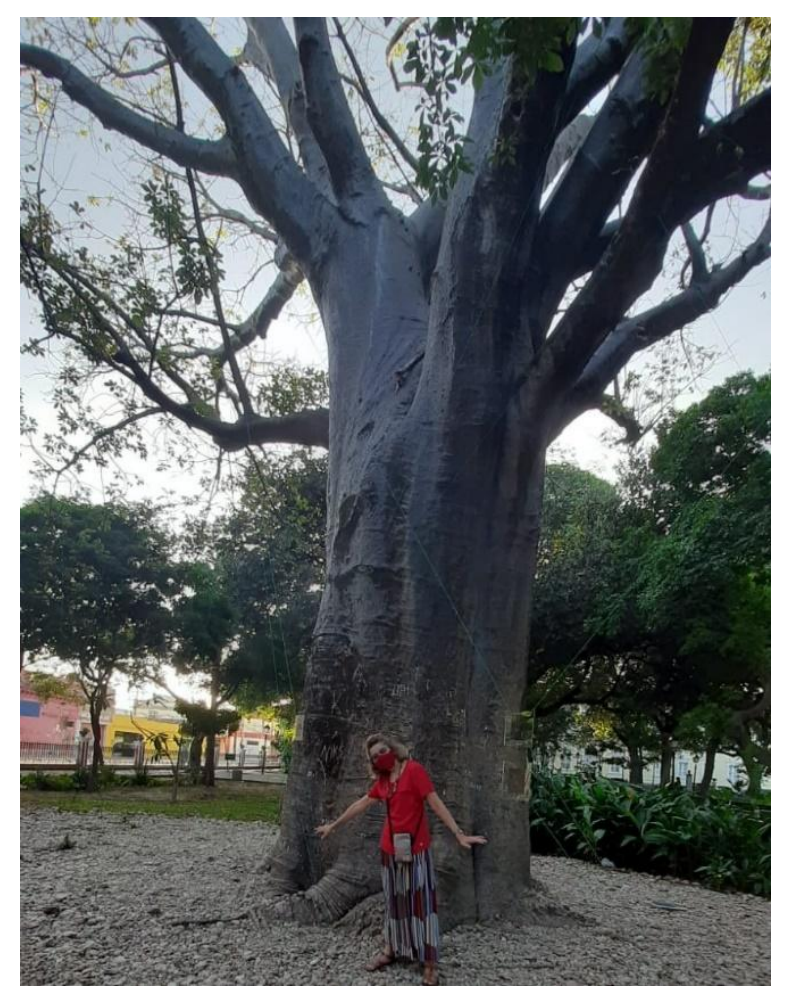

Fonte: autora acervo pessoal

Os sertões por onde andei e de onde sai sem que ele me largasse, encontra-se nas entranhas de todas as obras de Gilmar, com uma força inventiva sempre presente, uma poética amorosa real, verdadeira, trazendo vidas, pessoas e suas obras e o mais importante: no contexto deles com seriedade e zelo.

\section{Considerações finais}

Ante o exposto, espero que o leitor tenha sentido quanto esta terra cearense deve a Gilmar de Carvalho e quão generoso ele sempre foi. De todos os livros e artigos de Gilmar colocados nas referências, somente um foi comprado por mim, todos os demais foram presentes dele. Com efeito, ele estava certo, quando disse sobre a importância do 


\section{RIF, Ponta Grossa/ PR Volume 19, Número 43, p.14-30, jul./dez. 2021}

pensamento, conceito, ideias serem compartilhadas em obra escrita, pois dessa forma, nossos discursos permanecem vivos apesar de nossa partida corpórea. No que depender de mim, Gilmar continuará falando e trazendo esses sertões, seus cordéis e rabecas em minhas salas de aulas e palestras, fazendo valer a dedicação de toda sua vida. Assim, ele segue entre nós como o Baobá, possibilitando sombra frondosa de acolhimento. Suas obras são sementes para a juventude que as lê, e vai promovendo frutos culturais para uma visão real desse Ceará mesmo.

\section{Referências}

ANDRADE, Mário. Danças dramáticas do Brasil.10, 20. e 3o. tomos. São Paulo:Livraria Martins Editora, 1959.

ANDRADE, Mário. Origem das Danças Dramáticas Brasileiras. RevistaBrasileira de Música. Vol. II. 1‥ Fascículo. Março de 1935. Rio de Janeiro.

CARVALHO, Gilmar de. Tirinete - Rabecas da tradição. Fotos de Francisco So usa, apresentação de Ana Miranda. Fortaleza: Expressão Gráfica e Editora, 2018.

CARVALHO, Gilmar de. Questões históricas do Ceará. Revista de Ciências Sociais, Fortaleza, v.45, n.1, 2014, p. 263-275.

CARVALHO, Gilmar de. A xilogravura de Juazeiro do Norte. Fortaleza: IPHAN, 2014.

CARVALHO, Gilmar de. Teatro Completo. Fortaleza: SECULT/CE, Edições Teatro José de Alencar, 2011.

CARVALHO, Gilmar de. Xilogravura: doze escritos na madeira. Apresentação: Francisco Régis Lopes Ramos. 2a.ed. - Fortaleza: Museu do Ceará, 2011

CARVALHO, Gilmar de. Lyra Popular - o cordel em Juazeiro. Fortaleza: Museu do Ceará, 2011.

CARVALHO, Gilmar de. Teatro completo. Fortaleza: SECULT/CE, Edições Teatro José de Alencar, 2011.

CARVALHO, Gilmar de. Memórias da Xilogravura. Fortaleza: Expressão gráfica, 2010.

CARVALHO, Gilmar de. Cem Patativa. Fortaleza: OMNI Editora, 2009.

CARVALHO, Gilmar de. Mestres da cultura tradicional popular do Ceará. Fortaleza: SECULT/CE 2006. 


\section{RIF, Ponta Grossa/ PR Volume 19, Número 43, p.14-30, jul./dez. 2021}

CARVALHO, Gilmar de. Rabecas do Ceará.Francisco Sousa, fotógrafo - Fortaleza: Expressão Gráfica e Editora Ltda, 2006.

CARVALHO, Gilmar de. Artes da Tradição: mestres do povo. Fotos de Francisco Sousa. Fortaleza: Expressão Gráfica/Laboratório de Estudos da Oralidade UFC/UECE, 2005.

CARVALHO, Gilmar de. Mestres santeiros, Retábulos do Ceará. Fortaleza: Museu do Ceará/ Secretaria da Cultura do estado do Ceará, 2004.

CARVALHO, Gilmar de. Patativa poeta pássaro de Assaré. Fortaleza: Omni Editora Associados Ltda, 2002.

CARVALHO, Gilmar de. Patativa do Assaré. Fortaleza: Edições Demócrito Rocha, 2000.

CARVALHO, Gilmar de. Madeira matriz: cultura e memória. São Paulo: Annablume, 1998.

MAZULO JUNIOR, Paulo Antônio da Costa. 0 teatro de mamulengos do Mestre Pedro Boca Rica como veículo educativo e elemento socializador. Fortaleza, 2005. 69f. Monografia (Especialização em Arte e Educação) Centro Federal de Educação Tecnológica do Ceará.

BARROSO, Oswald. Ceará Mestiço. - Fortaleza: Expressão Gráfica e Editora, 2019.

PIMENTEL, Altimar de Alencar. Teatro de raízes populares. João Pessoa:Edição do Autor, 2003.

SOUZA, Maria de Lourdes MACENA de. Sendo como se fosse - as danças dramáticas na ação docente do ator professor. Belo Horizonte, 2014. 295f. Tese (Doutorado em Artes) EBA. Universidade Federal de Minas Gerais. Disponível em http://www.bibliotecadigital.ufmg.br/dspace/handle/1843/JSSS-9GFHGX 